\title{
Stadelmaier, Michael, Die Colletio Sangermanensis XXI titulorum. Eine systematische Kanonessammlung der frühen Karolingerzeit. Studien und Edition
}

\section{Philippe Depreux}

\section{OpenEdition}

\section{Journals}

Édition électronique

URL : http://journals.openedition.org/ifha/2150

DOI : 10.4000/ifha.2150

ISSN : 2198-8943

Éditeur

IFRA - Institut franco-allemand (sciences historiques et sociales)

Référence électronique

Philippe Depreux, «Stadelmaier, Michael, Die Colletio Sangermanensis XXI titulorum. Eine systematische Kanonessammlung der frühen Karolingerzeit. Studien und Edition ", Revue de l'IFHA [En ligne], Date de recension, mis en ligne le 01 janvier 2010, consulté le 22 septembre 2020. URL : http:// journals.openedition.org/ifha/2150; DOI : https://doi.org/10.4000/ifha.2150

Ce document a été généré automatiquement le 22 septembre 2020.

(CIFHA 


\title{
Stadelmaier, Michael, Die Colletio
} Sangermanensis XXI titulorum. Eine systematische Kanonessammlung der frühen Karolingerzeit. Studien und Edition

\author{
Philippe Depreux
}

La collection germanopratine en 21 titres, à l'édition de laquelle M.S. a consacré sa thèse de doctorat sous la direction de $\mathrm{H}$. Mordek, doit son nom à l'éditeur lui-même, qui veut ainsi assurer son identification au sein des collections canoniques jadis possédées par l'abbaye parisienne de Saint-Germain. Ce texte n'est pourtant pas spécialement lié à cet établissement, puisque le manuscrit éponyme (aujourd'hui conservé à la BnF) fut en réalité probablement copié à Fleury-sur-Loire. La diffusion manuscrite montre que ce document a joui d'une certaine audience au IXe siècle, même si elle ne peut être comparée à celle des grandes entreprises caractéristiques de l'âge de Charlemagne. Cette collection présente plusieurs particularités qui en font un document très intéressant : il s'agit notamment d'un ouvrage - une sorte de « vademecum à l'usage du clergé » - sous la forme didactique du dialogue, prisée à l'époque carolingienne - mais c'est le premier exemple du genre en matière de livres canoniques ; son auteur connaissait certains textes rares, comme la collection de Pithou, ce qui plaide en faveur d'une localisation dans un site majeur où l'on disposait d'une bonne bibliothèque. L'éditeur propose de situer l'élaboration de cette collection à Corbie, dont l'importance en matière de production de sources de droit canon a été particulièrement soulignée par les recherches récentes. Cette collection qui semble dater de la seconde moitié du VIIIe siècle et qui s'inscrit particulièrement bien dans la tradition monastique irlandaise, peut être considérée comme un témoignage précieux de la volonté de réforme des structures ecclésiastiques (renouveau de l'activité conciliaire, réaffirmation ou création d'une hiérarchie épiscopale) qui caractérise le milieu du VIIIe siècle en Gaule et en Germanie, ainsi que l'illustrent certaines définitions mises en 
exergue dans l'ouvrage. Il est par conséquent évident que l'édition critique de ce texte est précieuse, même si l'on peut regretter que l'auteur n'ait pas identifié toutes les citations de manière précise et exhaustive, en ne s'intéressant qu'au modèle (par exemple, la Collectio Hibernensis) sans toujours remonter à l'origine même des textes.

Philippe Depreux (Université de Limoges/ IUF) 